\title{
COMPARATIVE STUDIES OF THE SEATINGS OF PROPULSION PLANTSAND AUXILIARY MACHINERY ON CHOCKS MADE OF METAL AND CAST FROM RESIN
}

\author{
PART II. MOUNTING ON CAST RESIN CHOCKS
}

\author{
Paweł Grudziński \\ Konrad Konowalski \\ West Pomeranian University of Technology, Szczecin, Poland
}

\begin{abstract}
This article is Part II of the paper containing a description and results of the experimental studies of the deformations, friction processes and structural damping that occur in the foundation bolted joints of propulsion plant components and auxiliary machinery installed on sea-going ships. Part I of this research work presents an analysis of the rigid mountings of machines and devices to the foundations on steel or resin chocks, and explains the need to carry out relevant research in this area. It also presents the description and results of experimental studies carried out for a foundation bolted joint with a conventionally used steel chock. Part II (this article) contains a description and results of similar studies carried out for a foundation bolted joint with a modern chock-cast from epoxy resin compound (EPY), specially developed for this purpose. Then, a comparative analysis of the results obtained for both bolted joints in question was made and the foundation chocks of the poured-in-place resin compound were demonstrated to better fulfill their technical tasks than the steel chocks traditionally used for this purpose.
\end{abstract}

Keywords: sea-going ships, propulsion plants, auxiliary machinery, seating, bolted joints, chocks

\section{INTRODUCTION}

In Part I of this work it has been shown [4] that the traditional method of fastening propulsion plant components and auxiliary machinery to the structural foundations on sea-going ships, using for this purpose chocks made of metal (usually steel), has many significant disadvantages, both technical and economic. An appropriate seating of a main engine on steel chocks is very difficult, burdensome, timeconsuming and costly. And the effects of such a seating are characterised by low technical quality and high unreliability in operation. This creates many problems for the contractors and users of sea-going ships.

Significant progress in this area has been made by developing special pourable resin compounds for the chocks and a modern technology for the seating of machinery on the ships' structural foundations with their use. When cast, the resin flows readily into the whole area provided for the chock. The chock made in this way adheres closely to all surface irregularities. This eliminates the need for mechanical processing of the foundation to achieve a well fitted chock.

Originally, the principal purpose of the use of resin compounds for the chocks in the seating of propulsion plants and auxiliary machinery on ships' structural foundations, and in particular the main propulsion engines, was to simplify the mounting technology and shorten the installation time, by assuming that the technical quality of the mounting system will not be worse than that using the conventional steel chocks. This required the development of special resin compounds which had to meet a number of different 
conditions. The practical mounting of the main engines on the ships' structural foundations by using resin chocks required also to overcome many mental and formal barriers, posed by the designers and manufacturers of the main engines and sea-going ships, the classification societies and ship-owners. The resin compounds specially developed for this purpose not only simplified the installation technology, significantly shortened the time and reduced the cost of the mounting, but also provided a much better technical quality of the seatings. The practice shows that the use of resin chocks has a clear beneficial effect on the quality of the work, reliability and durability of the seated devices. It also noticeably reduces the level of vibration and noise. For the first time, engine security and alignment remain permanently excellent due to the perfect fit of the resin chocks compared with the conventional steel chocks. The latter allow the beating down of their contact surfaces and enable shifting of the engine, causing as a result its misalignment, nut loosening and finally, distortion of the foundation bolted joints [4].

The numerous advantages mean that the application of special resins, not only in the seating of the propulsion plants engine, but also many auxiliary machines and devices installed under and on the ship's deck, has now become the standard. The modern installation technology of machinery using resin chocks is now also applied more often and widely in the seating of different machines and devices exploited on land, in particular those that generate large dynamic forces and vibrations $[2,7]$.

The main objective of the studies presented in this paper is the scientific explanation of why the so-called rigid mountings of machines to the foundations using chocks cast from resin are technically better solutions, compared with the traditional solutions using steel chocks, despite the fact that the resin is a material of much lower strength and stiffness than steel.

To achieve this purpose, experimental studies have been carried out on suitable models of foundation bolted joints with a traditionally used steel chock or with a modern chock - cast from resin. Comprehensive results of these studies for the bolted joint with a steel chock have been presented in Part I [4]. Part II, presented in this article, contains the description and results of similar studies carried out for the bolted joint with a chock cast from resin. Then, a comparative analysis of the measurement results obtained for both studied joints has been made, demonstrating why the foundation chocks cast from resin in the seatings of machines meet their technical tasks better than the traditionally used steel chocks.

\section{A MODEL OF THE BOLTED JOINT WITH A RESIN CHOCK}

A model of the foundation bolted joint with a chock cast from resin is shown in Fig. 1.

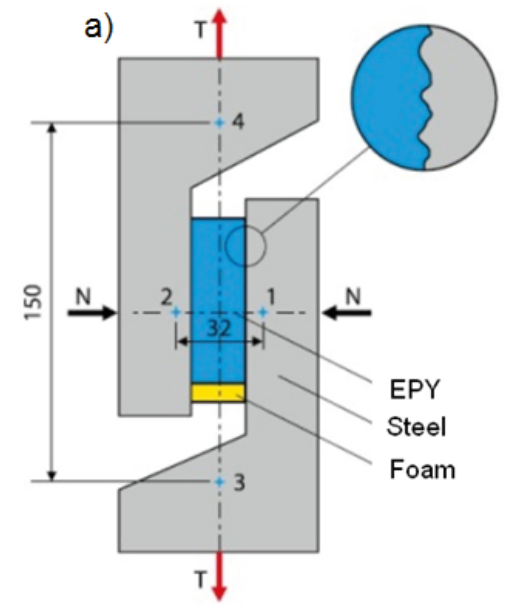

b)

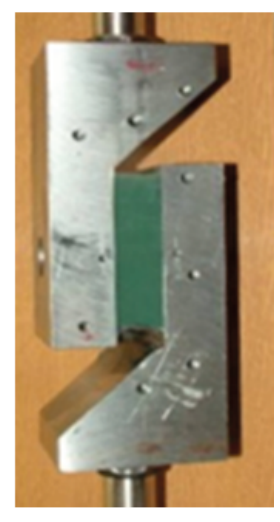

Fig. 1. The connected elements of the bolted joint with the chock cast from EPY resin: a) schematic, b) view

The dimensions of the connected elements (representing some clippings of the foundation plate and the machine base) and the chock are the same as in the earlier examined joint with the steel chock [4]. The EPY resin used for the chock is the result of many years of research efforts carried out at the Technical University of Szczecin (transformed in 2009 into the West Pomeranian University of Technology, Szczecin). This resin is among the world leaders in this field. It has all the certificates necessary for its wide use in the seating of all kinds of machinery and equipment on sea-going ships and on land. It has been applied practically in the seating of about 10,000 different machines and devices (including 2215 main engines) exploited on sea-going ships and platforms and for about 1350 machines and devices operating on land [3].

A resin chock (with dimensions $80 \times 80 \times 20 \mathrm{~mm}$ and with a hole $\Phi 24 \mathrm{~mm}$ in the centre) in the bolted joint provided for the experimental studies, has been cast already under the conditions applied in the practical seating of machines on foundations (described in detail in [5]).

An important thing in the preparation of the test joint was to secure it so that the contact surfaces of the cast resin chock and components to be connected were not separated or shifted relative to each other before the tests. The resin chock cast in this way automatically fits closely to all macroand micro-imperfections existing on the metal surfaces of the connected elements. In contrast to the contact between two metal surfaces, the real contact area in this case is equal to their nominal contact area, or even slightly greater than it, when taking into account the surface asperities. This ensures a continuity of the pressure distribution and a good transmission of the normal and tangential forces.

In the event of separation of the surfaces and their re-connection, even if it is conducted in a very careful manner, the contact conditions undergo some changes. Therefore, the object seated on chocks cast from resin after it has moved off may not be mounted on the same chocks. After its appropriate setting, new chocks must be cast. 


\section{EXPERIMENTAL STUDIES}

The experimental studies were performed on the testing machine INSTRON 8850, using appropriate hardware and software. Several experiments, similar or identical to those for the earlier tested joint with the steel chock, have been performed. The use of the same loading programs was not always possible, because the joint (with the resin chock) behaved quite differently from the joint with the steel chock studied earlier. For these studies, such conditions have been adopted which clearly revealed the qualitative and quantitative differences in the behaviour of the foundation bolted joints with the chocks made in the traditional manner with steel and the modern chocks cast from resin.

\section{EXPERIMENT NO. 1}

Experiment No. 1 in the studies of the joint with the resin chock had a slightly different course from the studies conducted previously for the joint with the steel chock. The tested joint was loaded and unloaded by a linearly time-varying force $\mathrm{T}$, according to an isosceles triangle with a gradually increasing height (Fig. 2a). The relative displacements of the connected elements (Fig. 1) were measured in the direction of the loading force $\mathrm{T}$. The course and results of this experiment are shown in Fig. 2, wherein $\tau$ is the mean value of the tangential stress acting on the chock induced by force $\mathrm{T}$.

These studies have shown that there is a clearly linear relationship between the average tangential stress $\tau$ (loading force T) and the relative displacement $\delta_{t}$ of the connected elements (measured at points 1 and 2 shown in Fig. 3). In this case, the frictional force, which balances the external load T, is proportional to the relative displacement $\delta_{t}$. These displacements are linear-elastic and form small hysteresis loops (Fig. 2b). The fields contained within these loops illustrate the energy dissipation in one loading cycle.

a)

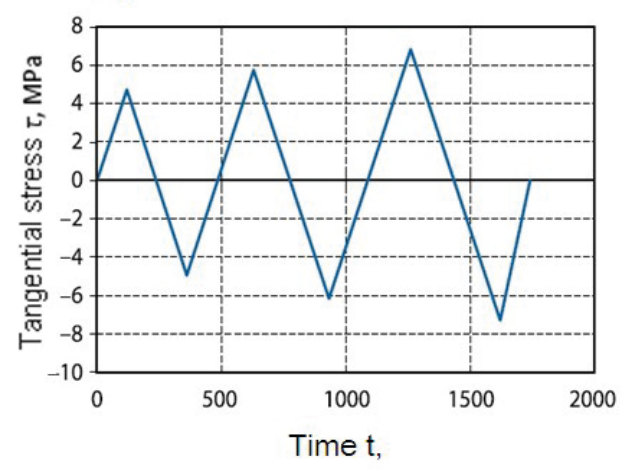

b)

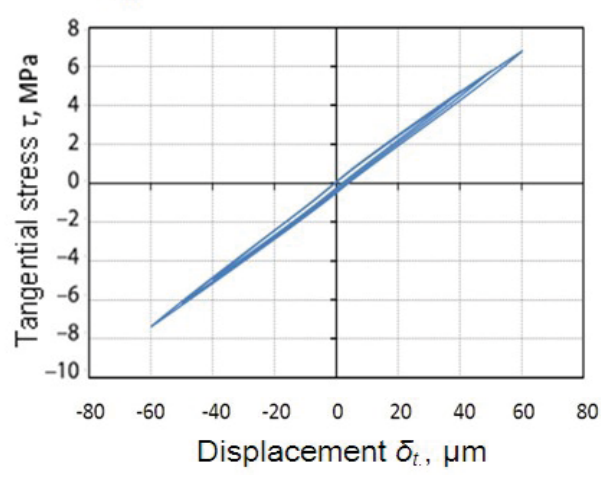

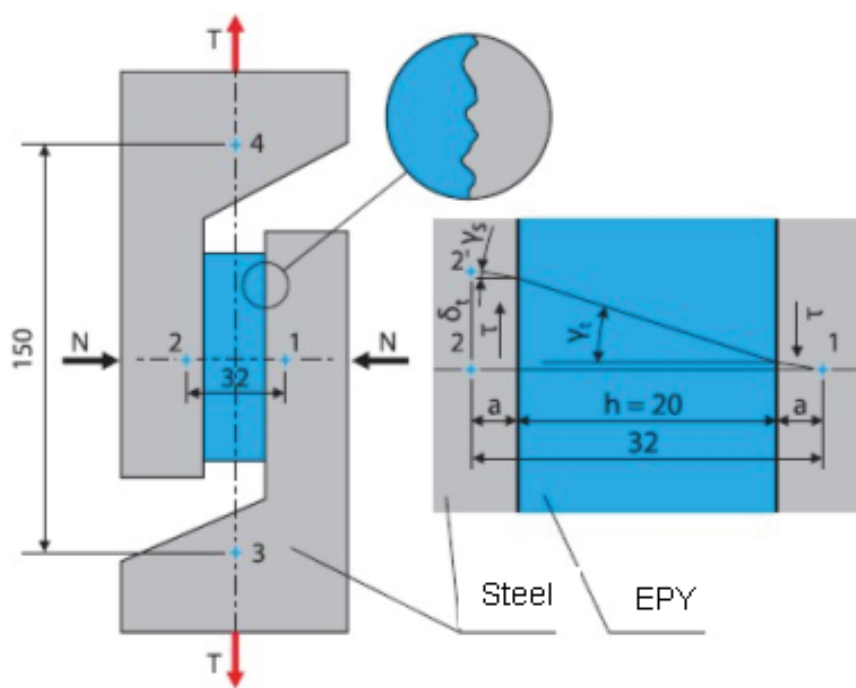

Fig. 3. Schematic diagram of loading and deformation of the tested joint with the resin chock

The characteristics obtained in these studies differ significantly from the characteristics previously obtained for the joint with the steel chock, both qualitatively and quantitatively. Fig. 3 shows schematically the loading and deformation of the tested joint with the resin chock. Considerable differences can be seen compared to the figure that illustrates the behaviour of the previously tested joint with the steel chock (see Part I [4], Fig. 4).

The relative displacements $\delta_{t}$ of the connected elements (measured at points 1 and 2), in the currently tested joint, are entirely due to the material's shearing strains of the joined elements, and most of all of the resin chock. The contact between the chock and the joined steel elements is intimate. There are neither contact deformations nor micro-slips in the contact interfaces. It should be noted that the resin chock was not glued to the connected steel elements. The surfaces of these elements have been covered with a thin layer of release agent (ACMOS 70 2406), and could be easily separated. The applied tangential loads were carried entirely by the static friction forces (without the occurrence of tangential contact deformations and micro-slips). Owing to the intimate adhesion of the resin chock to the rough metal surfaces, a very high value for the friction coefficient has been achieved. In this case, the friction coefficient reached a value of $\mu_{r}=0.8$, which was not its limit value. At this value of the friction coefficient, more than 3 times the limit value of the friction coefficient in the earlier examined joint with a steel chock, the system behaves in a linear-elastic way (Fig. 2). Greater loading for the test system was not used for fear of damaging the extensometers by a rapid break of the frictional connection. 


\section{EXPERIMENT NO. 2}

In experiment No. 2, the behaviour of the system was studied under a given program of forced oscillations (relative displacements measured at points 1 and 2). The oscillations had sinusoidal courses and were controlled with the extensometer No. 1 (see Part I [4], Fig. 3). The conditions of this experiment were the same as in the previous studies carried out for the joint with the steel chock. A schematic of the tested joint and points 1 and 2) are shown in Fig. 4. a)

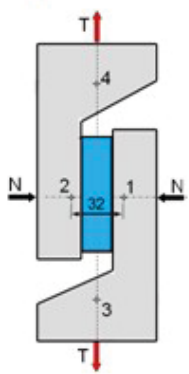

b)

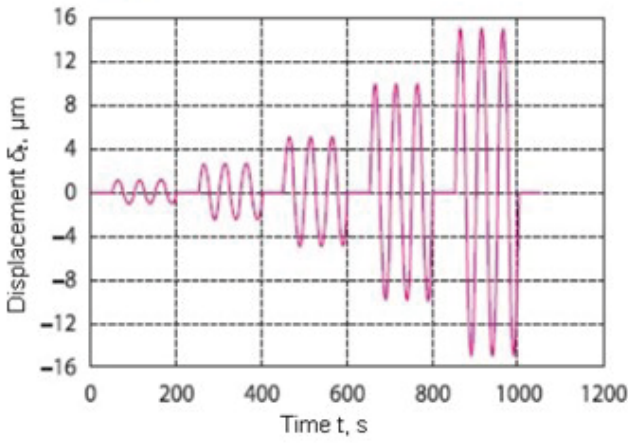

Fig. 4. Schematic of the tested joint (a) and the assumed program of oscillations (relative displacements of points 1 and 2) (b); amplitudes of these vibrations had values: $\delta_{a}=1,2.5,5,10$ and $15 \mu \mathrm{m}$ the given program of oscillations (relative displacements of

elements (measured at points 1 and 2), the force T executing the pre-programmed displacements, and the average shear stresses t acting on the chock, respectively. A simple linearelastic relationship between these quantities can be seen. The measured relative displacements of points 1 and 2 are mainly an effect of the shearing strains of the chock, and to a very small extent also of the connected elements (Fig. 3). Fig. $5 \mathrm{~d}$ shows the relationships between the tangential stresses and displacements and the hysteresis loops obtained in this experiment. These are all the loops obtained for the selected kinematic excitations with amplitudes of $1,2.5,5,10$, and $15 \mu \mathrm{m}$ (shown in Fig. 5a). They are an effect of the viscous damping occurring in the material of the chock. The results obtained (presented in Fig. 5) show that the tested joint with the cast resin chock behaves in a linear-elastic way. This is clearly visible in Fig. 5d. In this case, there are no micro-slips and structural damping.

Fig. 6 shows the hysteresis loop for the maximum amplitude of the relative displacements of the connected elements, measured at points 1 and 2 . From the graph we can easily determine the shear modulus $\mathrm{Gr}$ and the loss factor $\eta$ for the tested resin chock. The measured values of the relative displacements $\delta_{t}$ of the connected elements (measured at points 1 and 2) can be mathematically expressed as a sum (Fig. 3):

$$
\boldsymbol{\delta}_{\mathrm{t}}=\boldsymbol{\gamma}_{\mathrm{r}} \cdot \boldsymbol{h}+2 \cdot \boldsymbol{\gamma}_{\mathrm{s}} \cdot \boldsymbol{a}=\frac{\tau}{\mathrm{G}_{\mathrm{r}}} \cdot \boldsymbol{h}+2 \cdot \frac{\tau}{\mathrm{G}_{\mathrm{s}}} \cdot \boldsymbol{a}
$$

a)
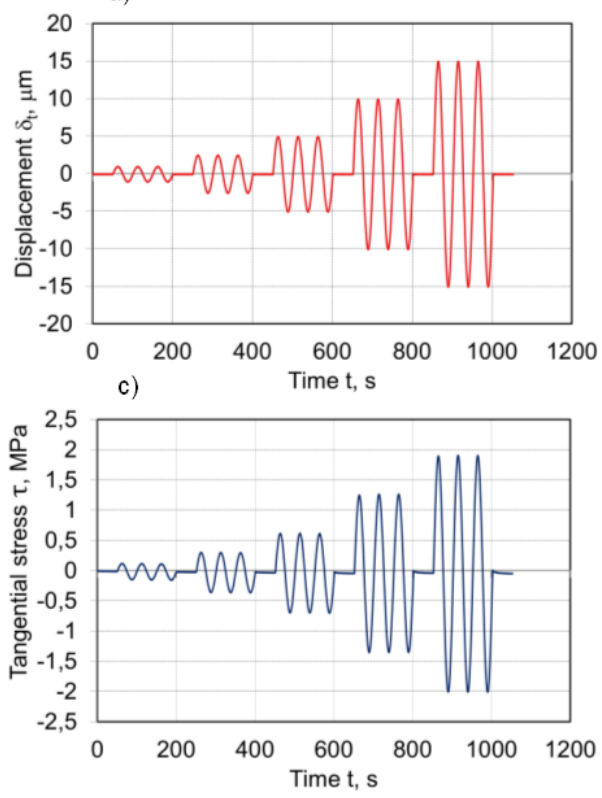

b)
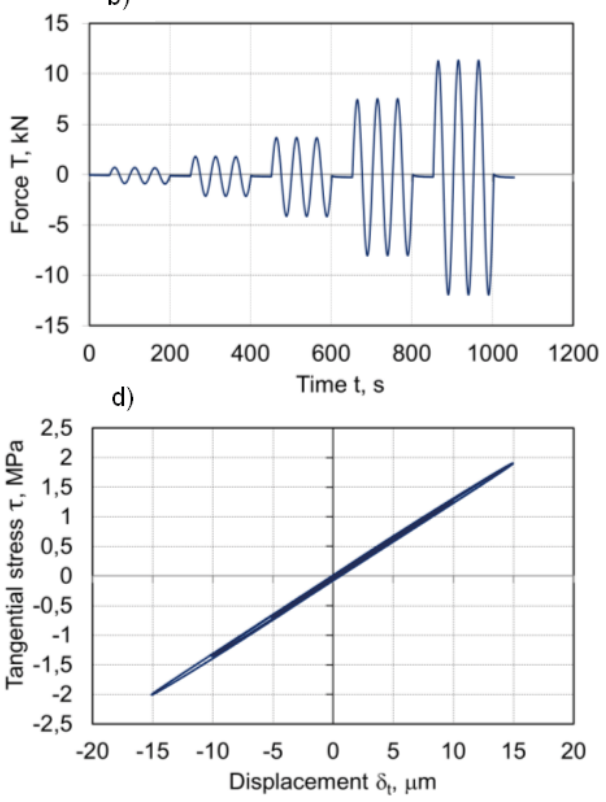

where:

$\gamma_{\mathrm{r}}$ - shearing strain angle of the resin EPY,

$\gamma_{s}$ - shearing strain angle of steel, $\mathrm{G}_{\mathrm{r}}$ - shear modulus of the resin EPY,

$\mathrm{G}_{\mathrm{s}}$ - shear modulus of steel; $\mathrm{G}_{\mathrm{s}}=$ 8.1•104 MPa, $a$ and $h-$ dimensions indicated in Fig. 3, mm.

Fig. 5. Results of experiment No. 2: a) time courses of the relative displacements $\delta$ of the connected elements, $b$ ) time courses of the force $T$ that produced the displacements, $c$ ) time courses of the average shear stresses $\tau$ acting on the chock, d) relationship between the stresses $\tau$ and displacements $\delta_{\text {t }}$

The results of this experiment, obtained from the testing machine, are shown in Fig. 5. Figs. 5a, b, and c show the time courses of relative displacements $\delta_{t}$ of the connected 


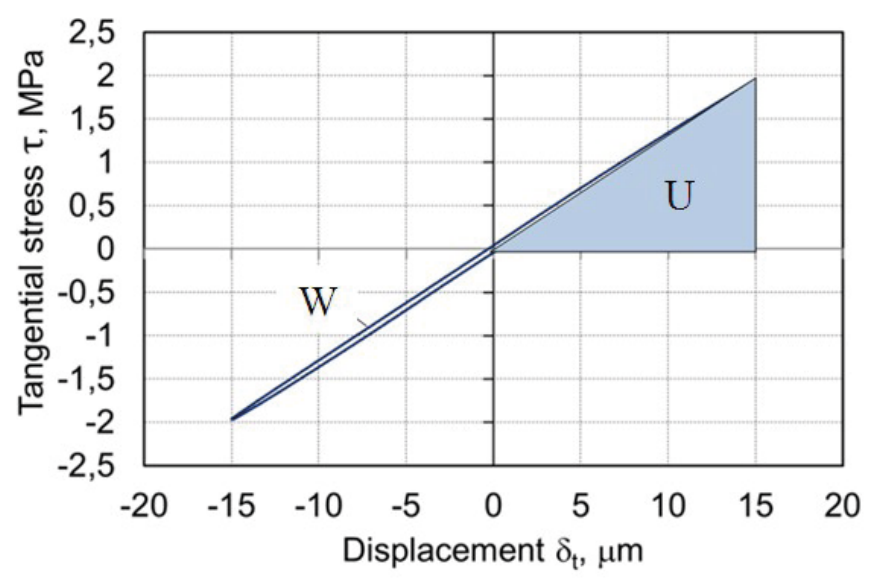

Fig. 6. Hysteresis loop for the maximum amplitude of the relative displacements of connected elements and the graphic designations of the values $W$ and $U$

From Eq. (1), after appropriate transformations, is obtained

$$
G_{r}=\frac{\tau \cdot h}{\delta_{t}-2 \cdot \frac{\tau}{G_{s}} \cdot a}
$$

The measurement results show (Fig. 6), that the relative displacement of the measuring points 1 and $2, \delta_{t}=0.015 \mathrm{~mm}$, has occurred for the average shear stress $\tau=1.95 \mathrm{MPa}$. Substituting these values into formula (2), by taking account of the data: $\mathrm{G}_{\mathrm{s}}=8.1 \cdot 104 \mathrm{MPa}, \mathrm{h}=20 \mathrm{~mm}$ and $\mathrm{a}=6 \mathrm{~mm}$, we obtained for the EPY resin the shear modulus $\mathrm{G}_{\mathrm{r}}=2651 \mathrm{MPa}$. The earlier determined value of the modulus of this material using a torsion pendulum [6] was $\mathrm{G}_{\mathrm{r}}=2511 \mathrm{MPa}$. a)

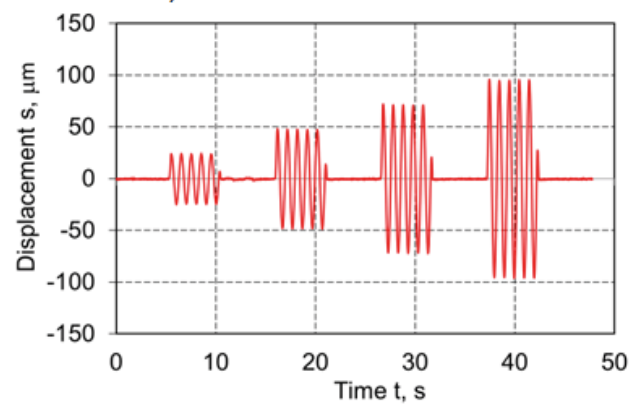

c)

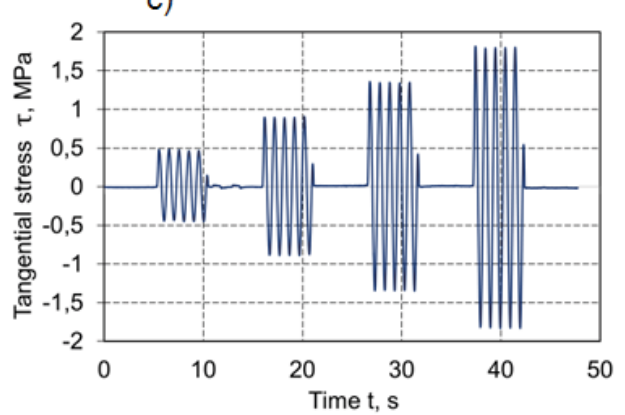

b)

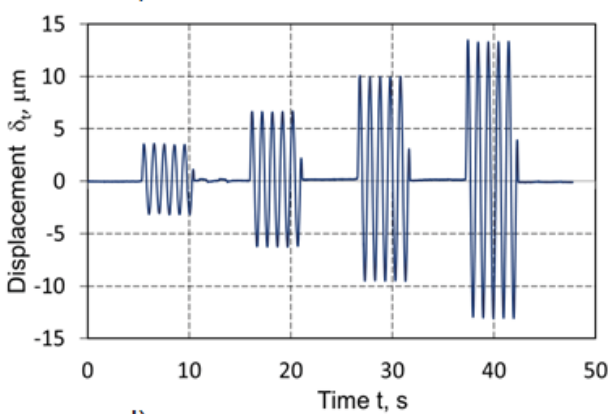

d)

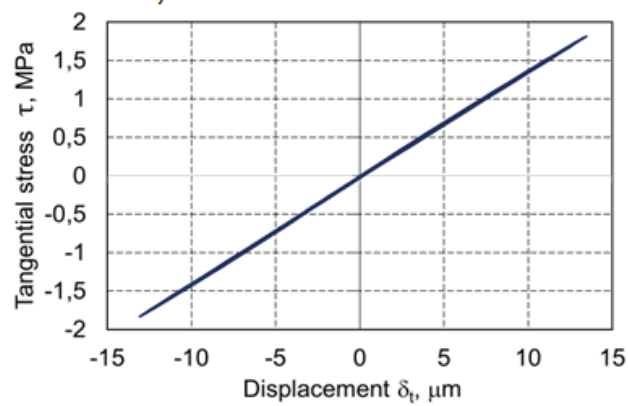

where $\mathrm{W}$ is the energy dissipated per cycle, related to the unit volume, and $U$ - the potential energy of the elastic deformation corresponding to the maximum deformation, related to the unit volume. For the hysteresis loop shown in Fig. 6, using a numerical integration, the following values were obtained: $\mathrm{W}=0.111 \mathrm{Nmm} / \mathrm{mm}^{3}, \mathrm{U}=0.72 \mathrm{Nmm} / \mathrm{mm}^{3}$. After substituting these values into (3), we obtained the loss factor $\eta=0.0245$.

\section{EXPERIMENT NO. 3}

In experiment No. 3 the test system was subjected to forced oscillations, controlled by the displacements $\mathrm{s}(\mathrm{t})$ of the testing machine's head. The conditions of this experiment were the same as in the earlier studies carried out for the bolted joint with the steel chock. The program of the assumed sinusoidal waveforms (with amplitudes of 25, 50, 75 and $100 \mu \mathrm{m}$, and frequency $v=1 \mathrm{~Hz}$ ), executed on the testing machine, is shown in Fig. 7a. Fig. 7b shows the time course of the relative displacements $\delta_{t}(t)$ of the connected elements, measured at points 1 and 2. Fig. 7c shows the time courses of the average tangential stresses acting on the chock, and Fig. 7c-the relationships between the stresses and displacements for the selected oscillations shown in Fig. 7a.

This study has shown that there are very simple linear-elastic relationships here between all the tested quantities. The bolted joint with the cast resin chock behaves quite differently from the earlier studied joint with the steel chock, where there were large nonlinearities, considerable micro-slips and large structural damping in the contact interfaces.

Fig. 7. Results of experiment No. 3: a) time courses of the selected displacements $s(t)$ of the testing machine's head, $b$ ) time course of the relative displacements $\delta_{t}(t)$ of the connected elements (measured at points 1 and 2), c) time course of the average shear stresses acting on the chock, $d$ ) relationships between the stresses $\tau$ and displacements $\delta_{t}$ 


\section{COMPARATIVE ANALYSIS OF THE RESULTS}

For comparison purposes, only some results of the studies were used. Fig. 8 shows the characteristics that illustrate the relationships between the tangential stress $\tau$ (force $T$ ) and the relative tangential displacement $\delta_{t}$ of the connected elements (measured at points 1 and 2) for the bolted joint with the steel chock and for the same joint with the chock cast from resin (EPY), respectively. Already at first glance, relevant quantitative and qualitative differences in the behaviour of the studied bolted joints can be seen. These differences are important from the point of view of both the engineering practice and theory.

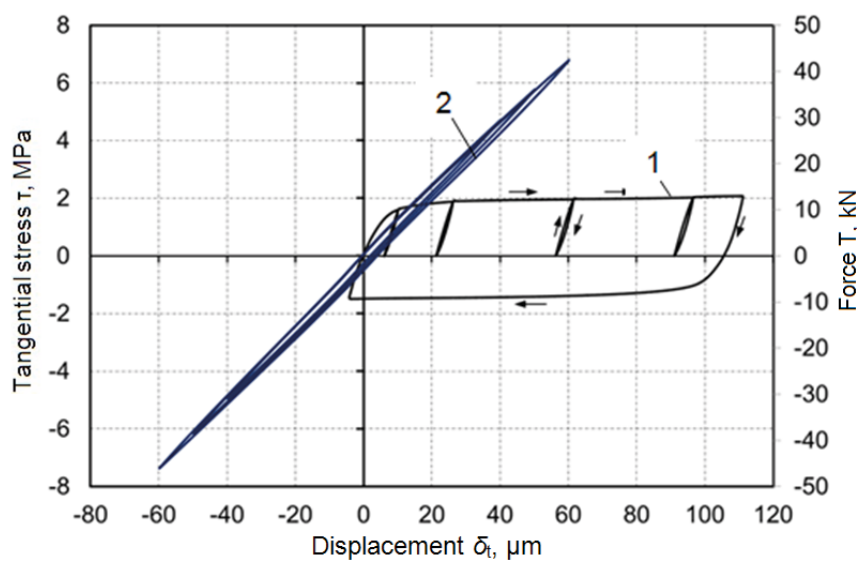

Fig. 8. Relationships between tangential stress $t$ (force T) and displacement $\delta_{t}$ of the connected elements for the tested joints with the steel chock (curve 1) and with the chock cast from resin (curve 2)

The characteristic of the relative displacements of the connected elements for the joint with the steel chock, from the very beginning, is nonlinear (Fig. 8, curve 1). With the increase of the tangential load, considerable displacements occur here. They are of an elastic-plastic nature. The relatively large displacements are mainly the result of micro-slips occurring in the contact interfaces of the interacting rough surfaces (see Part I [4], Fig. 5). These micro-slips occur at very small increments of tangential loadings (shear stresses) and can reach significant values before breaking the contact and the occurrence of macro-slip. The share of the elastic displacements is in this case very small. The elastic displacements are the result of the elastic deformations occurring in the material of the elements combined and the elastic tangential contact deformations occurring in their frictional interfaces. The characteristics and values of the elastic deformations are illustrated in the graphs obtained during unloading and re-loading of the tested joint (Fig. 8, curve 1).

Curve 2 in Fig. 8 presents the characteristic of the relative tangential displacements of the connected elements (measured at points 1 and 2), for the tested joint with the chock cast from EPY resin. This characteristic was determined during loading and unloading of the tested joint with the force T operating on two sides and gradually increasing its maximum value (see Fig. 2). The tested system shows linear-elastic behaviour. In this case, the measured displacements are the result of the elastic shearing strains occurring in the material of the joined elements, mainly in the chock (Fig. 3). The interacting surfaces of the chock and the joined elements adhere intimately to each other and can carry much greater tangential loads than the joint with the steel chock for the same clamping force. There are no noticeable tangential contact deformations and microslips in the interfaces, even when the loading force is 3.3 times higher than the maximum loading force acting on the tested joint with the steel chock. The test system behaves similarly during its tension and compression, and the hysteresis loops occurring in this case are small and have the form of sharpedged ellipses. Since no sliding movement into the contact interfaces occurs here, there is also no structural damping. Some slight damping occurs in the chock's material and is of a viscous nature.

Fig. 9 shows a comparison of characteristics illustrating the relationships between the frictional force (defined as $\mathrm{f}=\mathrm{T} / \mathrm{N}=\tau / \mathrm{p}$ ) and tangential displacement $\delta_{\mathrm{t}}$, determined experimentally for the tested bolted joints with the chock made of steel and the chock cast from resin. The maximum value of the friction coefficient determined for the steel chock is $\mu_{\mathrm{s}}=0.24$, and for the chock cast from resin is $\mu_{\mathrm{r}}=0.8$. This is 3.3 times greater than the boundary friction coefficient obtained for the bolted joint with the steel chock. In this case, it is not the maximum limit value of this friction coefficient, exceeding which will break the frictional connection and cause the occurrence of macro-slip. Due to the fear of damaging the extensometers, further increase of the loading force $\mathrm{T}$ (until the frictional connection is broken) was discontinued.

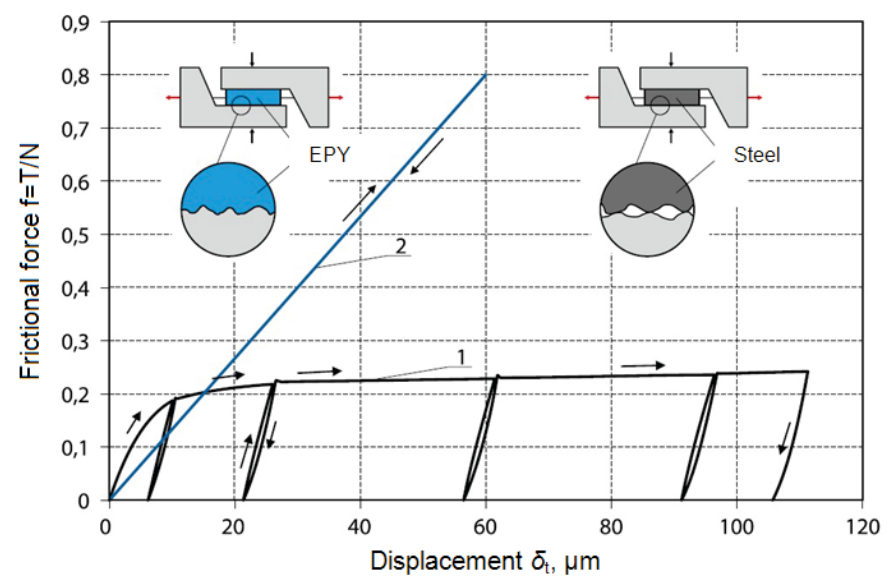

Fig. 9. Comparison of characteristics illustrating the frictional force $(f=T / N)$ displacement $\left(\delta_{t}\right)$ relationships for the tested bolted joints with the chock made of steel (curve 1) and the chock cast from resin (straight line 2)

Fig. 10 shows (for comparison purposes) the dynamic characteristics determined for the two tested bolted joints. The tests were performed at identical sinusoidal excitations shown in Fig. 10a, controlled at the measuring points 1 and 2 (Fig. 10b). The amplitudes of the excitations amounted to $1,2.5,5,10$ and $15 \mu \mathrm{m}$. Temporary shear stress waveforms and hysteresis loops occurring at these excitations are shown: for the joint with the steel chock - in Figs. 10c and 10d, and for the joint with the cast resin chock - in Figs. 10e and 10f. 
Figures $10 \mathrm{c}$ and $10 \mathrm{~d}$ show that in the tested bolted joint with the steel chock, even at relatively small excitations, there are nonlinear elastic-plastic relationships between the tangential forces T (average stresses $\tau$ ) and displacements $\delta_{t}$. These are caused by the tangential contact deformations and substantial micro-slips occurring in the contact interfaces of the interacting metal surfaces. They manifest themselves clearly in the large hysteresis loops. The friction forces powerfully dampen vibrations during a short interval of time. However, over a longer period, abrasion of the tops of the rough surfaces that are in contact occurs. Fretting corrosion is frequent. These phenomena lead to degradation of the interacting surfaces, loosening the bolted joints and increasing the vibrations in the seated machines, and finally to rapid wear of certain components of the machines, and emergency situations.

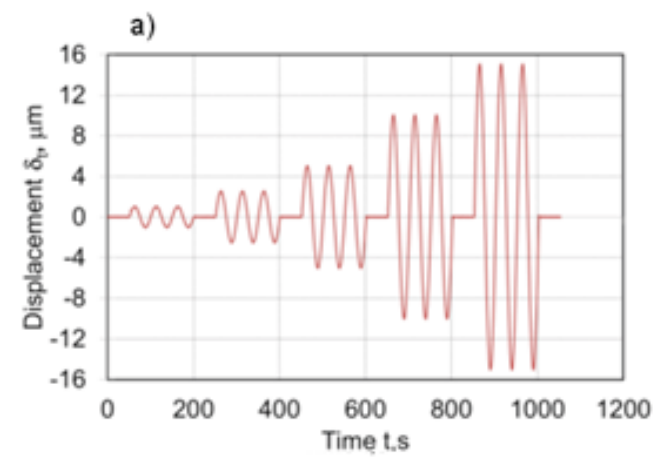

b)

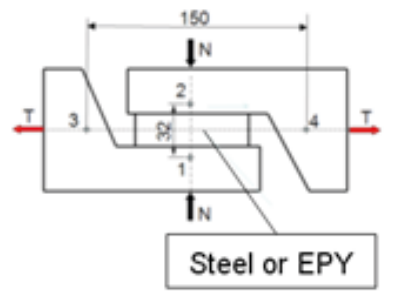

d)

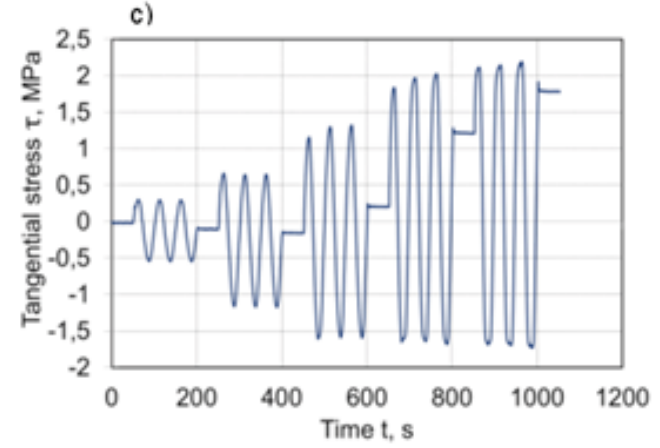

e)

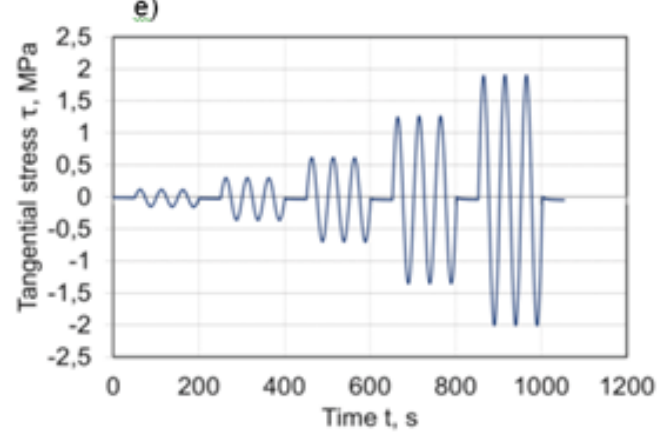

The bolted joint with the chock cast from resin behaves quite differently at the same excitations. For the entire range of excitations, there are simple linear-elastic relationships between the tangential forces (stresses) and displacements (Figs. 10e, f). In this case, there are no micro-slips of the interacting surfaces, and the measured displacements are only the result of the linear-elastic shear strain of the material of the connected elements, and especially of the resin chock. The hysteresis loops are small and form sharp-ended ellipses. They illustrate the viscous damping occurring in the material of the chock. In this case, the vibration energy flows from the machine to the foundation without violating the integrity of the fastening system or large losses. There are no microslips and structural damping. A small portion of the energy that is absorbed by the material of the chock converts into heat and is dissipated. This does not cause any (practically significant) degradation of the chock's material.

Due to the absence of microslips, neither abrasive wear nor any fretting phenomenon is observed. The large value of the effective friction coefficient $\left(\mu_{r}=0.8\right)$, without the occurrence of microslips in the contact interface, ensures a good transmission of large tangential forces (transversal to the axis of the bolt) by this kind of bolted joint. Such a system will be stable over a long period of time. It has a high reliability and durability. These facts have been confirmed in practice on many devices exploited in extremely difficult conditions.

The knowledge of these facts, in addition to its purely practical significance, is of great theoretical importance. It facilitates the modelling and calculation of such bolted joints and analysis of their impact on the dynamics of the whole complex mechanical system in which they are present.

Fig. 10. Vibrations planned and implemented on the testing machine (a), schematic diagram of the tested joints $(b)$ and comparison of the test results obtained for the joint with the steel chock $(c, d)$ and for the joint with the cast resin $\operatorname{chock}(e, f)$ 


\section{REMARKS AND CONCLUSIONS}

The experimental studies conducted and the comparative analysis of the results obtained show clearly and explain why resin chocks poured in the place of their application meet their technical tasks better than the traditional steel chocks used for this purpose.

The major practical advantages of chocks cast from resin are the simplicity of their implementation in any location and their very good fit to the bearing surfaces of the foundation and the machine base. They eliminate the need for mechanical treatment of the foundation and the chocks and their burdensome individual fitting in their place of use. These chocks are resistant to the prolonged action of mechanical loadings, atmospheric factors and various aggressive substances. They provide a good barrier to the propagation of structure-borne sounds. Due to the occurrence of linear-elastic relationships between the loads and deformations, they are easy to model and analyse.

From the conducted studies there follows a general conclusion that, without an accurate knowledge of the physical phenomena occurring in the so-called rigid fastening systems of machines and devices to the foundations, one cannot today properly understand, pose and solve problems that aim to reduce the level of vibrations and noise, and increase the systems' reliability and durability. This is an important and timely issue, due to the fact that the fastening systems of heavy machines and devices are very often the weakest links in the whole mechanical system in which they are present, and have a substantial impact on their dynamics, reliability and durability.

\section{REFERENCES}

1. Cherry E., Church J. E. (2014): Shipboard Maintenance of Machinery. Engine Foundations. ITW Chockfast Marine Industrial Grouts, Adhesives, Repair Products and Coatings. Retrieved from: http://www.chockfast.com/reference.html.

2. Grudziński K., Autor I., Jaroszewicz W., Ratajczak J. (2012): Practical applications of EPY plastic in machinery and equipment installation (in Polish). Technologia i Automatyzacja Montażu, 1/ 2012 (75), 18-23.

3. Grudziński K., Jaroszewicz W., Ratajczak J., Urbaniak M., Autor I. (2014): Mounting of machines and devices using EPY resin (in Polish). PPH ZAPOL, Dmochowski \& Sobczyk Registered Partnership, Szczecin 2014.

4. Grudziński P., Konowalski K. (2019): Comparative Studies of the Seatings of Propulsion Plants and Auxiliary Machinery on Chocks Made of Metal and Cast of Resin. Part I. Mounting on Steel Chocks. Polish Maritime Research, 4(104) 2019, 26, 142-148.

5. Grudziński P. (2013): Research into the Vibration Isolating Properties of EPY Resin and the Possibility of Its Use to Reduce the Vibrations and Insulation of Structure-Borne Sound (in Polish). Sprawozdanie merytoryczne z wykonania projektu badawczego nr N N502 194938, Zachodniopomorski Uniwersytet Technologiczny w Szczecinie, Katedra Mechaniki i Podstaw Konstrukcji Maszyn, Szczecin 2013 (unpublished).

6. Grudziński P. (1999): Modeling and testing of elasticdamping properties of plastics used in the seating of machines (in Polish). Dissertation, Politechnika Szczecińska, Katedra Mechaniki i Podstaw Konstrukcji Maszyn, Szczecin, 1999.

7. Kuly J. A. (2010): Best Practices in Compressor Mounting. ITW Technologies. $7^{\text {th }}$ Conference of EFRC, October 2122, Florence 2010.

8. VDI-Richtlinien 2062. Blat 1. Schwingungsisollierung, Begriffe und Methoden (Vibration insulation - Terms and definitions and methods), VDI e. V., Düsseldorf 2009.

\section{CONTACT WITH THE AUTHORS}

\author{
Paweł Grudziński \\ e-mail:pawel.grudzinski@zut.edu.pl \\ Zachodniopomorski Uniwersytet Technologiczny \\ w Szczecinie \\ al. Piastów 19, 70-310 Szczecin \\ Polska \\ Konrad Konowalski \\ e-mail:konrad.konowalski@zut.edu.pl \\ Zachodniopomorski Uniwersytet Technologiczny \\ w Szczecinie \\ al. Piastów 19, 70-310 Szczecin \\ POLSKA
}

